\title{
ESSENTIAL NORM AND COMPACTNESS OF THE PRODUCT OF DIFFERENTIATION AND COMPOSITION OPERATORS ON BLOCH TYPE SPACES
}

\begin{abstract}
XIANGLING ZHU
Abstract. In this paper, we give a complete characterization of the compactness of the product of differentiation and composition operators on Bloch type spaces and little Bloch type spaces. Moreover, an estimate of the essential norm for this operator on Bloch type spaces is also given.

Mathematics subject classification (2010): 30H25, 47B38.

Keywords and phrases: Bloch type space, essential norm, compactness, composition operator.
\end{abstract}

\section{REFERENCES}

[1] C. Cowen And B. Maccluer, Composition Operators on Spaces of Analytic Functions, CRC Press, Boca Raton, FL, 1995.

[2] N. DANFord AND J. SchwartZ, Linear Operators I, New York: Interscience Publishers, Jon Willey and Sons, 1958.

[3] R. Hibschweiler AND N. Portnoy, Composition followed by differentiation between Bergman and Hardy spaces, Rocky Mountain J. Math. 35 (2005), 843-855.

[4] H. LI AND X. FU, A new characterization of generalized weighted composition operators from the Bloch space into the Zygmund space, J. Funct. Spaces Appl. Volume 2013, Article ID 925901, 12 pages.

[5] S. Li And S. Stević, Reimann-Stieltjes type integral operators on the unit ball in $\mathbb{C}^{n}$, Complex Var. Elliptic Equ. 52 (2007), 495-517.

[6] S. Li And S. STEvić, Composition followed by differentiation between Bloch type spaces, J. Comput. Anal. Appl. 9 (2007), 195-205.

[7] S. Li AND S. STEVIĆ, Composition followed by differentiation from mixed-norm spaces to $\alpha$-Bloch spaces, Sb. Math. 199 (2008), 1847-1857.

[8] S. Li AND S. STEVIĆ, Cesàro type operators on some spaces of analytic functions on the unit ball, Appl. Math. Comput. 208 (2009), 378-388.

[9] S. Li And S. Stević, Composition followed by differentiation between $H^{\infty}$ and $\alpha$-Bloch spaces, Houston J. Math. 35 (2009), 327-340.

[10] S. Li AND S. STEVIĆ, Products of composition and differentiation operators from Zygmund spaces to Bloch spaces and Bers spaces, Appl. Math. Comput. 217 (2010), 3144-3154.

[11] Y. LIANG AND Z. ZHOU, Essential norm of the product of differentiation and composition operators between Bloch-type space, Arch der Math. 100 (2013), 347-360.

[12] Z. Lou, Composition operators on Bloch type spaces, Analysis 23 (2003), 81-95.

[13] B. MACCLUER AND R. ZHAO, Essential norm of weighted composition operators between Bloch-type spaces, Rocky. Mountain J. Math. 33 (2003), 1437-1458.

[14] K. Madigan And A. Matheson, Compact composition operators on the Bloch space, Trans. Amer. Math. Soc. 347 (1995), 2679-2687.

[15] J. Manhas And R. ZhaO, New estimates of essential norms of weighted composition operators between Bloch type spaces, J. Math. Anal. Appl. 389 (2012), 32-47.

[16] S. Ohno, K. Stroethoff And R. ZhaO, Weighted composition operators between Bloch-type spaces, Rocky Mountain J. Math. 33 (2003), 191-215. 
[17] S. STEVIĆ, Essential norms of weighted composition operators from the $\alpha$-Bloch space to a weightedtype space on the unit ball, Abstr. Appl. Anal. Vol. 2008, Article ID 279691, (2008), 11 pages.

[18] S. STEvić, Products of composition and differentiation operators on the weighted Bergman space, Bull. Belg. Math. Soc. Simon Stevin, 16 (2009), 623-635.

[19] S. STEVIĆ, On an integral-type operator from logarithmic Bloch-type and mixed-norm spaces to Bloch-type spaces, Nonlinear Anal. TMA 71 (2009), 6323-6342.

[20] S. STEVIĆ, Norm and essential norm of composition followed by differentiation from $\alpha$-Bloch spaces to $H_{\beta}^{\infty}$, Appl. Math. Comput. 207 (2009), 225-229.

[21] S. STEVIĆ, Weighted differentiation composition operators from $H^{\infty}$ and Bloch spaces to $n$-th weigthed-type spaces on the unit disk, Appl. Math. Comput. 216 (2010), 3634-3641.

[22] S. STEVIĆ, Weighted differentiation composition operators from mixed-norm spaces to weighted-type spaces, Appl. Math. Comput. 211 (2009), 222-233.

[23] S. STEVIĆ AND S. I. UEKI, Integral-type operators acting between weighted-type spaces on the unit ball, Appl. Math. Comput. 215 (2009), 2464-2471.

[24] M. TJANI, Compact composition operators on some Möbius invariant Banach space, $\mathrm{PhD}$ dissertation, Michigan State University, 1996.

[25] Y. WU AND H. Wulan, Products of differentiation and composition operators on the Bloch space, Collet. Math. 63 (2012), 93-107.

[26] H. Wulan, D. Zheng And K. Zhu, Compact composition operators on BMOA and the Bloch space, Proc. Amer. Math. Soc. 137 (2009), 3861-3868.

[27] W. YAng, Products of composition differentiation operators from $\mathscr{Q}_{K}(p, q)$ spaces to Bloch-type spaces, Abstr. Appl. Anal. Volume 2009, Article ID 741920, 14 pages.

[28] W. YANG AND X. ZHU, Generalized weighted composition operators from area Nevanlinna spaces to Bloch-type spaces, Taiwanese J. Math. 16 (2012), 869-883.

[29] R. ZHAO, Essential norms of composition operators between Bloch type spaces, Proc. Amer. Math. Soc. 138 (2010), 2537-2546.

[30] R. ZHaO, Composition operators from Bloch type spaces to Hardy and Besov spaces, J. Math. Anal. Appl. 233 (1999), 749-766.

[31] J. Zhou AND X. ZHU, Product of differentiation and composition operators on Bloch type spaces, Publ. Inst. Math., to appear.

[32] K. ZHU, Operator Theory in Function Spaces, Marcel Dekker, New York and Basel, 1990.

[33] K. ZHU, Bloch type spaces of analytic functions, Rocky Mountain J. Math. 23 (1993), 1143-1177.

[34] X. ZHU, Generalized weighted composition operators on weighted Bergman spaces, Numer. Funct. Anal. Opt. 30 (2009), 881-893.

[35] X. ZHU, Generalized weighted composition operators from Bloch spaces into Bers-type spaces, Filomat 26 (2012), 1163-1169. 